University of Nebraska - Lincoln

DigitalCommons@University of Nebraska - Lincoln

Publications, Agencies and Staff of the U.S.

Department of Commerce

U.S. Department of Commerce

2011

\title{
The application of GIS and spatiotemporal analyses to investigations of unusual marine mammal strandings and mortality events
}

\author{
Stephanie A. Norman \\ University of California - Davis, whaledoctor@gmail.com \\ Jessie Huggins \\ Cascadia Research Collective \\ Tim E. Carpenter \\ University of California - Davis \\ James T. Case \\ University of California - Davis \\ Dyanna M. Lambourn \\ Washington Department of Fish and Wildlife \\ See next page for additional authors \\ Follow this and additional works at: https://digitalcommons.unl.edu/usdeptcommercepub \\ Part of the Environmental Sciences Commons
}

Norman, Stephanie A.; Huggins, Jessie; Carpenter, Tim E.; Case, James T.; Lambourn, Dyanna M.; Rice, Jim; Calambokidis, John; Gaydos, Joseph K.; Hanson, M. Bradley; Duffield, Deborah A.; Dubpernell, Sandra; Berta, Susan; and Klope, Matt, "The application of GIS and spatiotemporal analyses to investigations of unusual marine mammal strandings and mortality events" (2011). Publications, Agencies and Staff of the U.S. Department of Commerce. 297.

https://digitalcommons.unl.edu/usdeptcommercepub/297

This Article is brought to you for free and open access by the U.S. Department of Commerce at DigitalCommons@University of Nebraska - Lincoln. It has been accepted for inclusion in Publications, Agencies and Staff of the U.S. Department of Commerce by an authorized administrator of DigitalCommons@University of Nebraska - Lincoln. 


\section{Authors}

Stephanie A. Norman, Jessie Huggins, Tim E. Carpenter, James T. Case, Dyanna M. Lambourn, Jim Rice, John Calambokidis, Joseph K. Gaydos, M. Bradley Hanson, Deborah A. Duffield, Sandra Dubpernell, Susan Berta, and Matt Klope 
MARINE MAMMAL SCIENCE, **(*): ***_***(***2011)

(C) 2011 by the Society for Marine Mammalogy

DOI: $10.1111 /$ j.1748-7692.2011.00507.x

\section{The application of GIS and spatiotemporal analyses to investigations of unusual marine mammal strandings and mortality events}

STEPHANIE A. NORMAN

Graduate Group in Epidemiology, W. Miller Laboratory,

Vet-Med: Pathology, Microbiology, Immunology,

University of California, Davis,

One Shields Avenue,

Davis, California 95616, U.S.A.

E-mail:whaledoctor@gmail.com

\section{JESSIE HugGins}

Cascadia Research Collective,

218 1/2 W. Fourth Avenue,

Olympia, Washington 98501, U.S.A.

Tim E. CARPENTER

Center for Animal Disease Modeling and Surveillance (CADMS),

Department of Medicine \& Epidemiology,

School of Veterinary Medicine,

University of California at Davis,

Davis, California 95616, U.S.A.

\section{JAMES T. CASE}

California Animal Health and Food Safety Laboratory,

School of Veterinary Medicine,

University of California, PO Box 1770,

Davis, California 95617-1770, U.S.A.

DYANNA M. LAMBOURN

Washington Department of Fish and Wildlife,

7801 Phillips Road SW,

Lakewood, Washington 98498, U.S.A.

\section{JiM RICE}

Oregon Marine Mammal Stranding Network,

Marine Mammal Institute,

Oregon State University,

2030 SE Marine Science Drive,

Newport, Oregon 97365, U.S.A. 


\title{
John CALAmbokidis
}

Cascadia Research Collective, 218 1/2 W Fourth Avenue,

Olympia, Washington 98501, U.S.A.

JOSEPH K. GAYDOS

University of California Davis,

UC Davis Wildlife Health Center-Orcas Island Office,

942 Deer Harbor Road, Eastsound, Washington 98245, U.S.A.

M. BRADLEY HANSON

NOAA Fisheries,

Northwest Fisheries Science Center,

2725 Montlake Boulevard East,

Seattle, Washington 98112, U.S.A.

Deborah A. Duffield

Department of Biology,

Portland State University, PO Box 751,

Portland, Oregon 97207, U.S.A.

SANDRA DUBPERnELL

SUSAN BERTA

MATT KLOPE

Central Puget Sound Marine Mammal Stranding Network,

Orca Network,

2403 North Bluff Road,

Greenbank, Washington 98253, U.S.A.

\begin{abstract}
In 2006-2007, an unusually high number of harbor porpoises (Phocoena phocoena) stranded along the Washington and Oregon coastlines. Spatiotemporal analyses were used to examine their ability to detect clusters of porpoise strandings during an unusual mortality event (UME) in the Pacific Northwest using stranding location data. Strandings were evaluated as two separate populations, outer coast and inland waters. The presence of global clustering was evaluated using the Knox spatiotemporal test, and the presence of local clusters was investigated using a spatiotemporal scan statistic (space-time permutation). There was evidence of global clustering, but no local clustering, supporting the hypothesis that strandings were due to more varied etiologies instead of localized causes. Further analyses at subregional levels, and concurrently assessing environmental factors, might reveal additional geographic distribution patterns. This article describes the spatial analytical tools applied in this study and how they can help elucidate the spatiotemporal epidemiology of other UMEs and assist in determining their causes. More than one spatial analytical technique should be used if the study objective is to detect and describe clustering in time and space and to generate hypotheses regarding causation of marine mammal disease and stranding events.
\end{abstract}


Key words: epidemiology, harbor porpoise, GIS, Phocoena phocoena, spatiotemporal analyses, unusual mortality event.

Recent outbreaks of disease in humans and animals have motivated public health agencies and researchers to develop early disease outbreak detection systems utilizing nondiagnostic information (Kallen et al. 1985, Norström et al. 2000, Mostashari et al. 2003). Establishing these systems can involve many challenges relative to data collection, analytical methods, and response. Analytical challenges include dealing with unknown time, place, and size of an outbreak, trying to adjust for natural spatial and temporal variations, and the lack of suitable population-at-risk data. While detection of disease clustering in time or space may be accomplished by mapping or plotting cases as a time series, it may be difficult to detect and visualize the interaction between time and space. The use of geographic information systems (GISs) and spatial statistical analyses is needed to fully explore time-space clustering of disease and mortality events precisely (Ward and Carpenter 2000a). GIS and spatial epidemiological analyses have been used in several applications in marine mammal disease research, including mapping of strandings to demonstrate disease and mortality events (Dietz et al. 1989, Harris and Gupta 2006), surveillance and monitoring of diseases (Jores et al. 2008), disease cluster detection (Miller et al. 2004), identification of environmental predictors of disease in wildlife populations (Miller et al. 2002), risk assessments (Hung et al. 2004, 2007), and modeling the spread and impact of disease (Norman 2008).

Increased effort to examine live- and dead-stranded marine mammals has helped to improve our knowledge of mortality rates and causes, allowing a better understanding of population threats and stressors, as well as our ability to determine when a stranding situation is "unusual" as seen in strandings involving Toxoplasma gondii, Cryptococcus gattii, and morbilliviruses (Gulland et al. 2002, Kreuder et al. 2003, Miller et al. 2004, Norman et al. 2011, Rowles et al. 2011). Understanding and investigating marine mammal unusual mortality events (UMEs), which are unexpected strandings that involve a substantial die off of a marine mammal population, is important because these events can serve as indicators of ocean health, giving insight into larger environmental issues, which may have implications for human health and animal welfare (Gulland 2006). Investigations of UMEs and the formation of a Working Group on Marine Mammal Unusual Mortality Events (WGMMUME) were mandated by Title IV of the U.S. Marine Mammal Protection Act, developed in 1992 in response to growing concerns about marine mammal die offs (Marine Mammal Protection Act 1992). The WGMMUME has criteria for declaring a UME, which help identify stranding events that are unusual (Gulland 2006).

In recent years, efforts to examine stranded marine mammal carcasses in order to better understand population threats and stressors have increased (MignucciGiannoni et al. 2000, Evans et al. 2005, de la Riva et al. 2009). Most analytical methods used to investigate strandings involve necropsies, mapping, and some use of GIS and spatial statistics (Kreuder et al. 2003, Greig et al. 2005, Harris and Gupta 2006). These geospatial methods are useful for helping to determine possible causes of strandings, but have not been applied to investigations of large-scale mortality events such as UMEs. The application of spatial analytical methods may be used in the context of UMEs to explore the interaction of space and time during mass strandings and potentially help identify or generate hypotheses as to the factor(s) 


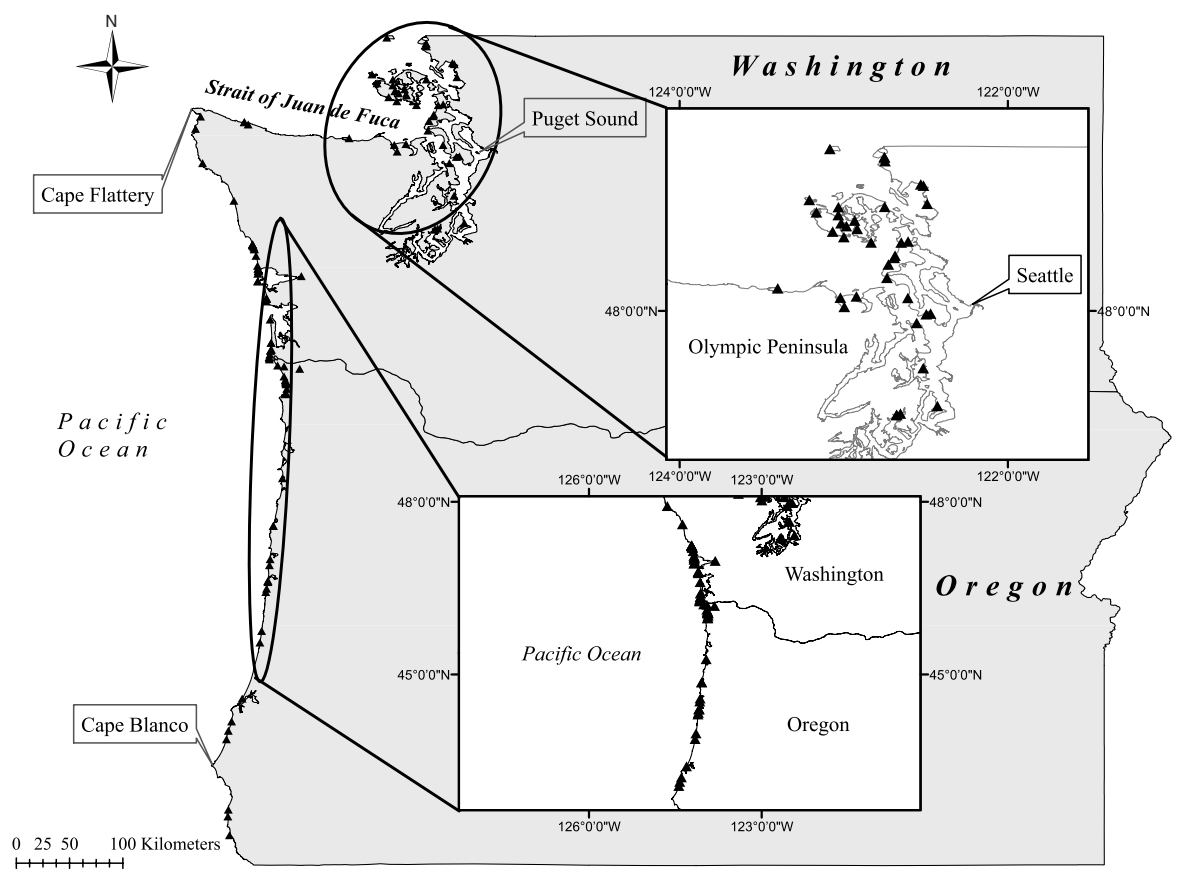

Figure 1. Harbor porpoise (Phocoena phocoena) strandings ( $\mathbf{\Delta})$ during a UME in the Pacific Northwest (2006-2007).

that contributed to the event. Strandings may be mapped, spatially and temporally analyzed, and used to model future events and develop surveillance and monitoring programs for marine mammal diseases (Norman 2008). Here, the application of spatial analytical methods for UME data was evaluated using data from a harbor porpoise (Phocoena phocoena) UME in the Pacific Northwest.

In the Pacific Northwest (Oregon and Washington), harbor porpoises are divided into two stocks: Washington Inland Waters and Oregon/Washington Coast Stock (Carretta et al. 2007), and are found in coastal waters of Washington and Oregon yearround (Fig. 1). Although no reliable data exist for harbor porpoise population trends in Oregon, Washington, or British Columbia, uncorrected estimates of abundance for the Oregon/Washington coast stock did not differ significantly between 1997 $(O=11,599)$ and $2002(O=11,036)(P=0.76)$, whereas uncorrected abundance estimates for the Washington inland stock significantly increased from 1996 to 2002/2003 (1,025 to 3,123; $P<0.0001)$ (Calambokidis et al. 1997, Laake et al. 1998, Carretta et al. 2007).

Since the 1970s, harbor porpoise stranding numbers in Oregon and Washington remained fairly consistent at $\sim 10-25$ per year (Norman et al. 2004b) despite increased reporting effort. In British Columbia, harbor porpoise strandings steadily increased since 1978 with increased reporting effort (Baird and Guenther 1995). In 2003, the number of strandings in Washington increased substantially to 34 (Norman et al. $2004 a, 2004 b$ ) and then dramatically increased in 2006 and 2007, with 64 and 50, respectively, being recorded. Due to the increased number of strandings reported 
in 2006 compared to years prior, and after consultation with the WGMMUME, a UME was declared in the Pacific Northwest on 3 November 2006 to facilitate the coordination of response and investigative efforts within the Northwest Region Stranding Network.

The UME, involving 114 harbor porpoises, continued through the end of 2007. The UME was officially declared over by the end of May 2008; however, any stranded porpoises documented during the first few months of 2008 were not included in the analyses as this time period was only used for post-UME monitoring of porpoise strandings (NOAA Fisheries, unpublished data). In addition to investigating the UME through necropsies, histopathology, and contaminant analyses, the need to spatially and temporally analyze the strandings was recognized. In this methodological article, we present and illustrate the Knox and the space-time permutation scan methods, to test for spatiotemporal clustering of harbor porpoise UME strandings over the entire study area (globally), and at more localized areas (locally), respectively (Knox 1964, Kulldorff et al. 2005). The purpose of this study was to test whether during this UME there were significant spatial and/or temporal clusterings of stranded porpoises in the outer coast $v$ s. inland waters populations.

\section{METHODS}

\section{Porpoise Data Set}

Harbor porpoise carcasses were recovered through NOAA Fisheries' Northwest Region Marine Mammal Stranding Network, encompassing Oregon and Washington and made up of cooperating stranding response organizations. Each porpoise stranding location was determined by geographic positioning expressed in latitude and longitude at the time of carcass recovery. Stranding date, county, state, inland waters or outer coast (for Washington State) were recorded, and when possible, sex and age class. Carcasses were processed as soon as possible (within $24-48 \mathrm{~h}$ of reporting). Age class was determined at necropsy by measurement of overall straight length (tip of beak to fluke notch), following the age class divisions in Read and Tolley (1997). Necropsies, as well as microscopic examination of major tissues, were performed on almost all of the carcasses by experienced individuals (NOAA Fisheries, unpublished data).

\section{Geographic Information System}

GIS has generally been used to analyze the relationships between potential risk factors and the occurrence of disease (incidence or prevalence) on a geographical basis through visual interpretation of maps (Ward and Carpenter 2000b). A disadvantage of data visualization is that it cannot indicate whether an aggregation of cases is actually due to a large number of cases or just to a large number of individuals in an area (Moore and Carpenter 1999).

For this study, a GIS (ArcGIS, version 9.3.1, ESRI, Redlands, CA) was used to spatially display stranding data points, along with maps of strandings by age class and sex (projection: World GCS 1984). A distinction between the inland waters and outer coast was made to reflect the differences in oceanic conditions and porpoise stocks between the two regions. Because harbor porpoise movements (Hanson 2007a) and intermixing rates are restricted in the North Pacific, and in following a risk adverse 
management strategy, two stocks are recognized: the Oregon/Washington Coast stock, occurring between Cape Blanco, Oregon, and Cape Flattery, Washington, and the Washington Inland Waters stock, in waters east of Cape Flattery (Fig. 1). Based on the geographic delineation of the two stocks of harbor porpoises, each spatiotemporal analysis was performed twice, once each for the two bodies of water.

\section{SpatioTemporal Tests}

Disease or mortality events may cluster in time and/or space, but not necessarily be due to local transmission from a contagious process. For instance, a global epidemic or event that has obvious temporal clustering may display a random spatial pattern. On the other hand, clustering might be noted in a specific geographic location, although these events may not display a specific temporal pattern. The methods described here focus on detecting clusters in space and time; in other words, to evaluate whether events that are close throughout the study region are also close throughout the study time period, and vice-versa (Ward and Carpenter 2000a).

In this study, two spatiotemporal cluster detection tests were performed to examine for clusters both globally and locally. Global indices of spatial association evaluate the propensity of spatial clustering across an entire region, while local indices of spatial association detect patterns in more locally defined geographic units (e.g., counties) that acutely deviate from neighboring units. Both tests use case (stranding) data and adjust for purely spatial and purely temporal clustering, and thus avoid confounding by differential reporting effort by location or season. The Knox test, a global cluster detection test, detects space-time interactions by categorizing points into near and far in space $v s$. near and far in time, based on critical space and time distances set by the user, and is not affected by nonuniform underlying population densities (Knox 1964). SaTScan is an analytic method that has been widely used for local cluster detection, and evaluation of outliers (Jackson et al. 2009).

\section{Global Cluster Detection}

Global clustering tests evaluate the relationship between cases and controls; clustering is present if cases are closer to other cases than they are to controls. Alternatively, clustering can also be determined by distance between cases if controls are not available (Kulldorff and Nagarwalla 1995). The Knox test was used in this analysis to separately test for global clusters within the two study areas (Knox 1964) using the SSTAT Spatial Statistics Program (version 4.70, University of California, Davis, CA). While the test has been used to investigate factors influencing outbreaks of disease in fish through cluster detection (Georgiadis et al. 2001), it has not yet been applied to marine mammal stranding analyses. It calculates the spatial and temporal distance separations of all strandings (case pairs). First, critical distances are determined, representing the space or time distance where disease transmission is believed to be possible. The critical time distance may represent the incubation period, and the space distance may represent host or vector (or current and wind) movement within that critical time period. After these critical periods are defined, the proportion of case pairs "close in time" is multiplied by the proportion of case pairs "close in space" to give the expected proportion of case pairs "close in time and space." The resulting expected proportion is multiplied by the total number of case pairs to give the number of case pairs expected to be both close in space 
and time. This result is compared with the observed number of case pairs that were close in space and time. If the observed number exceeds the expected, this indicates clustering. The probability of observing at least the number of observed case pairs that are close in time and space is calculated to determine significance (Carpenter 2001).

The total number of case pairs is $n(n-1) / 2$, where $n$ equals the number of cases (strandings). The number of case pairs examined in this study was 903 [(43 $\times 42) / 2]$, and $2,485[(71 \times 70) / 2]$, in the inland and outer waters, respectively. For this analysis, the following critical distances and times were selected: 1, 3, 5, $10 \mathrm{~km}$ and 7,14, $21 \mathrm{~d}$, respectively, to specify space and time separations between strandings, which are believed to be sufficiently close for an association between the strandings, that may imply either disease transmission between cases or sharing of a common stranding source. The number of stranding pairs that were less than or equal to the critical values was compared with the expected using the following equation:

$$
P(X \geq k)=\sum_{i=k}^{\infty} \frac{e^{-\lambda} \lambda^{i}}{i !}=1-\sum_{i=0}^{k-1} \frac{e^{-\lambda} \lambda^{i}}{i !},
$$

where $k$ is the number of observed stranding pairs that were close (less than the critical distance) in both space and time and $\lambda$ is the expected number of stranding pairs that were close in both space and time and is calculated as the proportion of stranding pairs that were close in space, times the proportion of stranding pairs that were close in time, times the number of stranding pairs.

\section{Local Cluster Detection}

Localized clustering tests divide the study area into subsets, called geographic units, which can be used to specify significantly elevated rates or cases of disease or events in these units, and identify these areas as a cluster. In this study, we present a prospective space-time permutation scan statistic for which population-atrisk data are not required, and which can be used for the early detection of disease outbreaks when only case numbers (no controls) are available. The scan may be used prospectively to regularly scan a geographical region for outbreaks or unusual events of any location and any size. For each location and size, potential one-day as well as multi-day outbreaks can be observed, in order to quickly detect a rapidly intensifying outbreak and still have sufficient power to detect a gradually emerging outbreak by combining data from multiple days (Kulldorff et al. 2005). Natural space by time interaction in many syndromic surveillance data sources may be due to factors other than disease outbreak such as foraging behavior, migration, currents, and other natural phenomena (Kulldorff et al. 2005).

Recent examples of applications of this to detect spatialtemporal disease clustering and strandings in wildlife and domestic animals include assessing the spatial distribution of chronic wasting disease in white-tailed deer (Odocoileus virginianus) in Wisconsin (Joly et al. 2003), evaluating the prevalence of bovine tuberculosis in wild badgers (Meles meles) in Ireland (Olea-Popelka et al. 2003), and assessment of causes of mortality in stranded southern sea otters in California (Enbydra lutris nereis) (Kreuder et al. 2003). 
A spatiotemporal permutation model was used to identify local spatiotemporal clusters (SaTScan version 7.0, Martin Kulldorff, Boston, MA; Kulldorff and Nagarwalla 1995, Kulldorff 1997, Kulldorff et al. 2005). SaTScan has been widely used for cluster detection on aggregated count data. For each centroid (i.e., geographic unit), many windows (circles or ellipses) are constructed, with varying sizes (and angles) sharing the same centroid. SaTScan was only evaluated with elliptical windows in this analysis because for most situations, the elliptic version has better power and precision compared with circular windows (Jackson et al. 2009). Through its continuously moving "window," the resulting scan statistic considers different sized aggregations of cases, thereby avoiding arbitrary geographical aggregation of the data. The number of observed strandings in a cluster was compared to what would have been expected if the spatial and temporal locations of all the strandings were independent of each other so that there was no space-time interaction. The statistic utilizes a probability model to calculate the observed number of strandings $(C)$ using only cases of strandings (i.e., no "controls") in a specific area $(s)$ during day $(d)$ :

$$
C=\sum_{s} \sum_{d} C_{s d}
$$

For each stranding and day, the expected number of cases $\left(\mu_{s d} \frac{1}{C}\right)$ is calculated, conditioning on the observed marginals:

$$
\left(\sum_{s} C_{s d}\right)\left(\sum_{d} C_{s d}\right) .
$$

A cluster of strandings would be detected in a particular geographic area if, during a specific time period, the area had a higher than expected number of strandings than surrounding areas. An infinite number of overlapping cylinders, jointly covering the entire study area, are obtained, with each cylinder reflecting a potential cluster, differing in size and shape. The likelihood function was maximized over all windows, identifying the window that constituted the likeliest stranding cluster. This is the cluster least likely to have occurred by chance. The likelihood ratio for this window is the maximum likelihood-ratio test statistic. The statistic's distribution under the null hypothesis and corresponding $P$-value were obtained by repeating the same analytic exercise on a large number of randomly selected replications of the data set generated under the null hypothesis (in a Monte Carlo simulation), resulting in 999 random data set replications being generated, where stranding times were randomly assigned to each stranding location (Ward and Carpenter 2000b). Clusters were said to be statistically significant if the rank of the likelihood function of the observed strandings was among the 50 largest simulated values, that is, $P \leq 0.050$.

\section{RESULTS}

A total of 114 harbor porpoises stranded from January 2006 through December 2007, 43 (37.8\%) in the inland waters of Puget Sound and the Strait of Juan de Fuca and $71(62.2 \%)$ on the outer coast of Washington/Oregon (Fig. 1). Females constituted $35(30.7 \%)$ of the strandings, males $43(37.7 \%)$, and unknown sex $36(31.6 \%)$. Age class distribution was as follows: $34(29.8 \%)$ adults, $36(31.6 \%)$ 


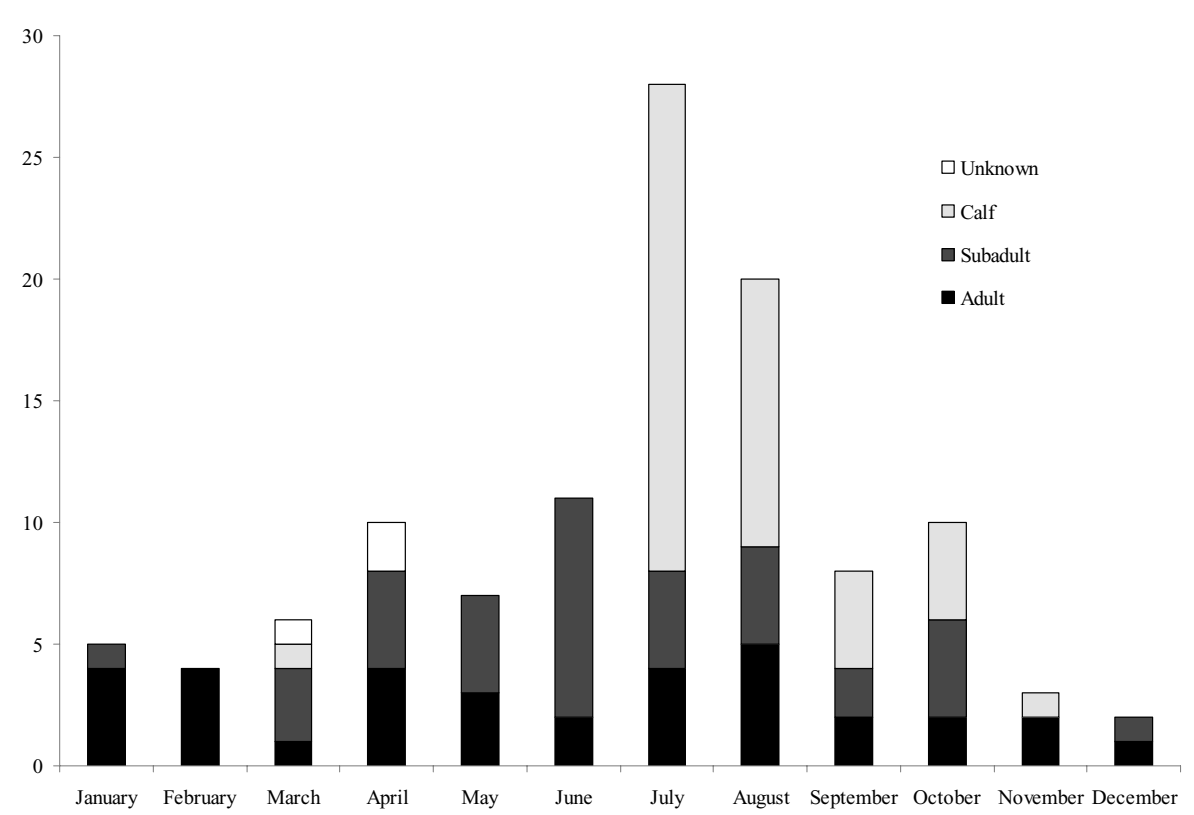

Figure 2. Harbor porpoise (Phocoena phocoena) strandings by month and age class during a UME in the Pacific Northwest (2006-2007).

subadults, $41(36.0 \%)$ calves, and $3(2.6 \%)$ were of unknown age class. Necropsies, conducted on 75 of 114 individuals, representing all age classes showed no consistent lesions that would have accounted for an unusual number of mortalities (NOAA Fisheries, unpublished data). Although there was an apparent increase in the number of strandings observed during the summer (June-August) compared to other seasons, it was not statistically significant (Kruskal-Wallis, $\chi^{2}=3.000, \mathrm{df}=3, P=0.392$ ), and therefore no trend was detected (Fig. 2). Calves stranded more than other age classes, but not significantly (Kruskal-Wallis, $\chi^{2}=3.000, \mathrm{df}=3, P=0.392$ ), and were heavily concentrated in the inland waters of Puget Sound. Statistically significant global clusters $(P \leq 0.050)$ were detected in inland waters for the following critical time/distances (days/kilometers): $14 / 1(P=0.022), 21 / 1(P=0.041), 7 / 3$ $(P=0.050)$, and $14 / 3(P=0.041)$. These critical pairs were further evaluated and found to be comprised of two adult males that stranded $7 \mathrm{~d}$ apart in Sekiu, Washington (they were caught in the same commercial gill net and were recovered and reported by the fishermen), and a calf that stranded $5 \mathrm{~d}$ before an adult female at nearly the same location (Blaine, Washington). No significant clusters were detected at the local level for either the outer coast or inland water strandings, $R R=4.45$, $P=0.158$ and $R R=4.44, P=0.549$, respectively.

\section{DisCUSSION}

The primary goal of this manuscript was to use the stranding event example to illustrate the utility and application of GIS and spatiotemporal analyses as part of an 
unusual stranding event investigation and to better understand the epidemiology of these incidents. A notable finding was the elevated number of stranded calves relative to other age classes (Read and Tolley 1997) (Fig. 2). Harbor porpoises normally calve from May through June, which could partially account for the elevated number of stranded calves (Bjørge and Tolley 2008). If harbor porpoise population levels recently increased, then an increase in calf strandings relative to other years would be observed. The late spring and summer pattern of strandings is consistent with previously reported harbor porpoise stranding patterns (Norman et al. 2004a), likely due to seasonality of the animals' movements and foraging habitat, and from increased reporting effort during better weather conditions and visitors to the coastline (Hanson $2007 b)$. A low proportion of cetacean deaths actually end up as strandings $(<10 \%)$, so even a small change in the proportion of deaths that wash ashore may appear as a significant change in strandings numbers, even if overall mortality has not changed (Williams et al. 2011). The magnitude of misrepresentation of stranding numbers when presenting observed carcass counts may be tempered by qualifying these numbers based on the species in question, its abundance, and survival rates (Williams et al. 2011).

When analyzing marine mammal stranding data, findings must be interpreted with caution as it cannot always be determined if the animal died in the vicinity of the stranding location, or elsewhere and then washed up at the site. However, it is expected that stranding patterns are already biased toward nonsignificant spatial patterns due to the influence of carcass drift, current, wind, or reporting effort. Therefore, the finding of any significant clustering during analyses warrants further investigation. Possible etiologies of this broad-scale event are discussed elsewhere (NOAA Fisheries, unpublished data), but briefly, might include changes in porpoise distribution in response to changes in prey distribution or predator avoidance, feeding habitat shifts, and carcass drift from wind and currents. Critical distances and times between a case (stranding) pair represent space and time separations where there may have been disease transmission or common exposure to two cases. The adult/calf pair cluster may have been related, but needs confirmation by genetic analysis. The significance of the two adult males stranding at the same location within $8 \mathrm{~d}$ of each other is presently unknown. The lack of evidence for localized clustering would likely exclude more contained etiologic causes such as harmful algal blooms or point-source events (e.g., bacterial outbreak or oil spill), as evidenced by lack of reported disease outbreaks shortly before or during the UME, and lack of pathological evidence of multiple deaths due to a single or predominant etiology.

In this study, stranding data were analyzed for two separate areas, inland waters and outer coast, to account for differences in habitat and range of these two groups of porpoises (Carretta et al. 2007) as well as oceanographic differences between the two habitats. However, when space-time permutation models are utilized, spatial and temporal biases are greatly minimized, particularly when the study period is shorter than a few years (Kulldorff et al. 2005). Cluster analyses have been used to study the distribution of causes of death in California sea lions (Zalophus californianus) (Greig et al. 2005), the spatial relationship between $T$. gondii serological status and stranding location of southern sea otters (Miller et al. 2002), and show great potential for use in the study of marine mammal diseases and large-scale mortality events (Norman 2008). In other spatial analyses of marine mammal strandings and diseases, a single type of spatial test was used (scan statistic) (Miller et al. 2002, Kreuder et al. 2003, Greig et al. 2005). In contrast, this study combined both global and local spatiotemporal tests to assess the presence of clustering on both scales since no one 
spatial analytical technique is considered better than others (Ward and Carpenter 2000b).

Methods used here to evaluate the presence of spatiotemporal clustering can be applied to other UME investigations to further explore stranding patterns and help elucidate potential causes of the event. Spatiotemporal tests are advantageous for use with stranding data in that they use only case data (control data not required), are not bound by population distribution assumptions, and adjust for purely spatial or purely temporal clustering, thereby eliminating potential confounding associated with data collection. To ensure sufficient study power, the Knox test was used to detect global clusters and the spatiotemporal scan statistic to detect local clustering. The Knox test has been used in veterinary epidemiology to examine Salmonella infections of horses, investigate fowl-cholera outbreaks in the Californian turkey industry, and to describe blowfly strike in Queensland sheep flocks (Carpenter $e t$ al. 1996, Paré $e t$ al. 1996, Ward and Armstrong 2000). Kulldorff et al. (1998) reported the power of the space-time scan statistic to be dependent on the shape of the cluster, number of cases in the data set, and the relative risk within and outside the cluster. They reported the space-time scan test had $80 \%$ power if the relative risk were 4.4 (similar to the values reported here) in order to detect a cluster of 10 cases. This study utilized well-established advantages of the space-time scan statistic such as adjusting for an inhomogeneous population density, searching for clusters without specifying their size or location in order to resolve preselection bias; delivering a single $P$-value, and using a likelihood ratio based statistic to take multiple testing into account (Viel et al. 2005).

A potential lack of power should be considered in studies that fail to detect space-time clustering when the sample size is <500 cases (Paré et al. 1996). A limitation of the Knox test is that it is heavily dependent on the critical time and space distances the researcher specifies. Ideally, these critical values should be selected based on known epidemiological characteristics of the disease or event of interest. In some cases, however, if the disease etiology and/or cause of stranding is unknown or poorly characterized, exploratory analyses can be useful. Contrary to being viewed as data "mining," exploratory analyses can provide useful information on factors that may have contributed to the cluster of events and may be thought of as hypothesisgenerating approaches (Ward and Carpenter 2000a). Another Knox test limitation is that the need to identify critical time and space distances also results in a loss of information, but is countered by the fact that the Knox test may be used for more qualitative data such as "near" vs. "far" spatial and temporal distances (Ward and Carpenter 2000a).

Advantages of the space-time permutation scan statistic method are that it requires only case data, is easy to use, makes minimal assumptions about the geographic location, time, or size of the outbreak or stranding event, while automatically adjusting for any natural purely spatial and purely temporal variation, and it allows adjustment for space by time interaction (Kulldorff et al. 2005). Another benefit is that it takes into account the linear nature of the outer coastline with an elliptical window to capture strandings along a linear coastline. An alternative to a circular window, the elliptical window shape provides a slightly higher power for true clusters that are long and narrow in shape, such as along a coastline. Lastly, this test also solves the problem of multiple testing when closely overlapping spatial areas and/or time intervals are being evaluated.

There are a number of limitations of the space-time permutation scan method. The method is highly sensitive to missing or incomplete data, which emphasizes 
the need for good data quality checks and analytic adjustments during the analyses (Kulldorff et al. 2005). It is also important to note that the geographical boundary of the detected event is not necessarily the same as the boundary of the true event. The less geographically condensed the event is, the less power (sensitivity) there is to detect it. In spite of these limitations, the space-time permutation scan statistic has the ability to perform without population-at-risk data which is often the case in dealing with wild marine mammal populations, where these data may be hard to obtain (Kulldorff et al. 2005). The stranding data used in this study also have some limitations. Some strandings went undetected because carcasses did not wash ashore or were washed back out to sea or scavenged before being discovered and reported. Furthermore, some strandings may not be clustered by easily defined units of analysis, as in the case of a point-source exposure occurring at the site of an oil spill or algal bloom. Use of a geographic unit (e.g., county) of stranding, rather than the stranding site itself, may provide greater power to detect nonpoint source-related unusual stranding events.

In conclusion, the results of the cluster detection tests indicate global clusters occurred throughout the strandings for both regions, suggesting that the cause(s) of mortality among these porpoises was not of a point-source type, but may have been generalized and varied toward a broader ecosystem-type source. Spatial epidemiology and GIS utilized during a UME investigation may help generate hypotheses as to the etiologic and geographic source(s) of contributors to strandings, or further refine and guide ongoing investigations of unusual mortalities. It would be ideal to be able to detect a UME in its early stages using spatial and temporal analytical tools; however, in the event that the cause(s) of a UME (that has already happened) is unknown, a retrospective analysis of the stranding data, such as this study, may give clues or generate hypotheses as to potential causes. Different types of spatial and temporal analytical tools may be applied prospectively to detect UMEs, or retrospectively analyze data on confirmed UMEs. In addition, spatiotemporal analytical tests could be used to analyze strandings not previously recognized as UMEs, to see if they were, in fact, unusual.

More than one spatial analytical technique should be used if the study objective is to detect and describe clustering in time and space and to generate hypotheses regarding causation of marine mammal disease and stranding events. It is also critical to consider the spatial and temporal model inherent in the techniques when interpreting results (Ward and Carpenter 2000a). These techniques add substantial information to disease and stranding investigations and provide the veterinary epidemiologist with a firm foundation on which to build causal hypotheses and implement more refined response and investigative strategies. When choosing a spatial analytical technique, ideally the investigator should determine the type of data to be analyzed (continuous, dichotomous or categorical, and point or area), what procedure will be examined (detection of clusters, interpolation, or diffusion), what spatial data are available, the appropriate scale for the analyses, existence of commercial software for the technique (vs. the necessity for custom programming), and the test's reported power. The challenge now is to employ these techniques as routine procedures within marine mammal disease and stranding investigation programs. Some issues that must be addressed in the future include the routine collection of spatial and temporal information from disease and stranding surveillance and monitoring programs, and the development of software that can be easily accessed, used and understood by veterinary epidemiologists and marine mammal researchers. Publication of more examples of the application of techniques to investigate spatial and 
temporal clustering of disease in veterinary epidemiology will assist epidemiologists and statisticians in addressing these issues.

\section{ACKNOWLEDGMENTS}

The authors thank the stranding volunteers and individuals involved in the response and recovery of animals during the UME, including A. Traxler and the San Juan County Marine Mammal Stranding Network, the volunteers of the Central Puget Sound Marine Mammal Stranding Network, S. Murphy, K. Wilkinson, B. Norberg, L. Barre, the members of the UME Working Group, and the volunteers of the Northwest Region Marine Mammal Stranding Network. We are grateful to S. Raverty for conducting the majority of the histopathology and ancillary testing associated with this UME. Funding for collection and examination of the animals was provided by grants to Stranding Network members from the John $\mathrm{H}$. Prescott Marine Mammal Rescue Assistance Grant Program, administered through the Office of Protected Resources (NOAA Fisheries). Valuable and constructive comments were received from J. Stein, NOAA Northwest Fisheries Science Center.

\section{Literature Cited}

Baird, R. W., and T. J. Guenther. 1995. Account of harbor porpoise (Phocoena phocoena) strandings and bycatches along the coast of British Columbia. Report of the International Whaling Commission (Special Issue 16):159-168.

Bjørge, A., and K. A. Tolley. 2008. Harbor porpoise Phocoena phocoena. Pages 530-533 in W. F. Perrin, B. Würsig and J. G. M. Thewissen, eds. Encyclopedia of marine mammals. 2nd edition. Academic Press, Burlington, MA.

Calambokidis, J., J. L. Laake and S. D. Osmek. 1997. Aerial surveys for marine mammals in Washington and British Columbia inside waters. Final Report by Cascadia Research, Olympia, WA, to National Marine Mammal Laboratory, AFSC, NMFS, Seattle, WA. 96 pp. Available from Cascadia Research, Olympia, WA. Available at http://www.cascadiaresearch.org/biblio.htm (accessed 8 August 2010).

Carpenter, T. E. 2001. Methods to investigate spatial and temporal clustering in veterinary epidemiology. Preventive Veterinary Medicine 48:303-320.

Carpenter, T. E., D. W. Hird and K. P. Snipes. 1996. A time-space investigation of the epidemiology of fowl cholera. Preventive Veterinary Medicine 28:159-163.

Carretta, J. V., K. A. Forney, M. M. Muto, J. Barlow, J. Baker, B. Hanson and M. Lowry. 2007. U.S. Pacific Marine Mammal Stock Assessments: 2006. U.S. Department of Commerce, National Oceanic and Atmospheric Administration Technical Memorandum, NOAA-TM-NMFS-SWFSC-398. 312 pp. Available from the Office of Protected Resources, NOAA Fisheries, Silver Spring, MD. Available at http://www.nmfs.noaa.gov/pr/pdfs/sars/po2006.pdf (accessed 1 August 2010).

de la Riva, G. T., C. K. Johnson, F. M. Gulland, G. W. Langlois, J. E. Heyning, T. K. Rowles and J. A. Mazet. 2009. Association of an unusual marine mammal mortality event with Pseodo-Nitzschia spp. blooms along the southern California coastline. Journal of Wildlife Diseases 45:109-121.

Dietz, R., M. P. Heide-Jørgensen and T. Harkönen. 1989. Mass deaths of harbor seals (Phoca vitulina) in Europe. Ambio 18:258-264.

Evans, K., R. Thresher, R. M. Warneke, C. J. A. Bradshaw, M. Pook, D. Thiele and M. A. Hindell. 2005. Periodic variability in cetacean strandings-links to large-scale climate events. Biology Letters 1:147-150.

Georgiadis, M. P., R. P. Hedrick, T. E. Carpenter and I. A. Gardner. 2001. Factors influencing transmission, onset and severity of outbreaks due to white sturgeon iridovirus in a commercial hatchery. Aquaculture 194:21-35. 
Greig, D. J., F. M. D. Gulland and C. Kreuder. 2005. A decade of live California sea lion (Zalophus californianus) standings along the central California coast: Causes and trends, 1991-2000. Aquatic Mammals 31:11-22.

Gulland, F. M. D. 2006. Review of the Marine Mammal Unusual Mortality Event Response Program of the National Marine Fisheries Service. U.S. Department of Commerce, NOAA Technical Memorandum NMFS-OPR-33, 37 pp. Available from the Office of Protected Resources, NOAA Fisheries, Silver Spring, MD. Available at http://www.nmfs.noaa.gov/pr/pdfs/health/mmume_review.pdf (accessed 4 April 2011).

Gulland, F. M. D., M. Haulena, D. Fauquier, G. Langlois, M. E. Lander, T. Zabka and R. Duerr. 2002. Domoic acid toxicity in Californian sea lions (Zalophus californianus): Clinical signs, treatment and survival. Veterinary Record 150:475-480.

Hanson, M. B. $2007 a$. Using location data from telemetry tagged marine mammals to improve stock assessments. Pages 62-63 in P. Sheridan, J. W. Ferguson and S. L. Downing, eds. Report of the National Marine Fisheries Service Workshop on Advancing Electronic Tag Technologies and Their Use in Stock Assessments. U.S. Department of Commerce, National Oceanic and Atmospheric Administration Technical Memorandum, NMFSF/ SPO-82. 82 pp.

Hanson, M. B. 2007b. Seasonal movements and habitat use of Dall's and harbor porpoises in the inland and coastal waters of Washington State as determined by radiotelemetry. Pages 53-54 in P. Sheridan, J. W. Ferguson and S. L. Downing, eds. Report of the National Marine Fisheries Service Workshop on Advancing Electronic Tag Technology and Their Use in Stock Assessments. U.S. Department of Commerce, National Oceanic and Atmospheric Administration Technical Memorandum, NMFSF/SPO-82. 82 pp.

Harris, D. E., and S. Gupta. 2006. GIS-based analysis of ice-breeding seal strandings in the Gulf of Maine. Northeastern Naturalist 13:403-420.

Hung C. L. H., M. K. So, D. W. Connell, et al. 2004. A preliminary risk assessment of trace elements accumulated in fish to the Indo-Pacific humpback dolphin (Sousa chinensis) in the northwestern waters of Hong Kong. Chemosphere 56:643-651.

Hung, C. L. H., R. K. F. Lau, J. C. W. Lam, et al. 2007 Risk assessment of trace elements in the stomach contents of Indo-Pacific humpback dolphins and finless porpoises in Hong Kong waters. Chemosphere 66:1175-1182.

Jackson, M. C., L. Huang, J. Luo, M. Hachey and E. Feuer. 2009. Comparison of tests for spatial heterogeneity on data with global clustering patterns and outliers. International Journal of Health Geographics 8:55.

Joly, D. O., C. A. Ribic, L. A. Langenberg, et al. 2003. Chronic wasting disease in Wisconsin free-ranging white-tailed deer. Emerging Infectious Diseases 9:599-601.

Jores, J., A. E. Derocher, C. Staubach and A. Aschfalk. 2008. Occurrence and prevalence of Clostridium perfringens in polar bears from Svalbard, Norway. Journal of Wildlife Diseases 44:155-158.

Kallen, A., P. Arcuri and J. D. Murray. 1985. A simple model for the spatial spread and control of rabies. Journal of Theoretical Biology 116:377-93.

Knox, G. 1964. The detection of space-time interactions. Applied Statistics 13:25-29.

Kreuder, C., M. A. Miller, D. A. Jessup, et al. 2003. Patterns of mortality in southern sea otters (Enhydra lutras nereis) from 1998-2001. Journal of Wildlife Diseases 39:495-509.

Kulldorff, M. 1997. A spatial scan statistic. Communications in statistics: Theory and methods 26:1481-1496.

Kulldorff, M., and N. Nagarwalla. 1995. Spatial disease clusters: Detection and inference. Statistical Methods 14:799-810.

Kulldorff, M., W. F. Athas, E. J. Feuer, B. A. Miller and C. R. Key. 1998. Evaluating cluster alarms: A space-time scan statistic and brain cancer in Los Alamos, New Mexico. American Journal of Public Health 88:1377-1380.

Kulldorff, M., R. Hefferman, J. Hartman, R. Assunção and F. Mostashari. 2005. A spacetime permutation scan statistic for disease outbreak detection. PLOS Medicine 2:02160224. 
Laake, J., J. Calambokidis and S. Osmek. 1998. Survey report for the 1997 aerial surveys for harbor porpoise and other marine mammals of Oregon, Washington and British Columbia outside waters. Pages 77-97 in P. S. Hill and D. P. DeMaster, eds. MMPA and ESA implementation program, 1997. AFSC Processed Report 98-10. 246 pp. Available from National Marine Mammal Laboratory, 7600 Sand Point Way NE, Seattle, WA.

Marine Mammal Protection Act of 1972 (1992 Amendment). 1992. Title IV-Marine Mammal Health and Stranding Response. Title 16 United States Code, Chapter 31, Sec. 1421. 1992 edition.

Mignucci-Giannoni, A. A., G. M. Toyos-Gonzalez, J. Perez-Padilla, M. A. Rodriguez-Lopez and J. Overing. 2000. Mass stranding of pygmy killer whales (Feresa attenuata) in the British Virgin Islands. Journal of the Marine Biological Association of the United Kingdom 80:759-760.

Miller, M. A., I. A. Gardner, C. Kreuder, et al. 2002. Coastal freshwater runoff is a risk factor for Toxoplasma gondii infection of southern sea otters (Enbydra lutris nereis). International Journal for Parasitology 32:997-1006.

Miller, M. A., M. E. Grigg, C. Kreuder, et al. 2004. An unusual genotype of Toxoplasma gondii is common in California sea otters (Enhydra lutris nereis) and is a cause of mortality. International Journal for Parasitology 34:275-284.

Moore, D. A., and T. E. Carpenter. 1999. Spatial analytical methods and geographic information systems: Use in health research and epidemiology. Epidemiologic Reviews 21:143-161.

Mostashari, F., M. Kulldorff, J. J. Hartman, J. R. Miller and V. Kulasekera. 2003. Dead bird clustering: A potential early warning system for West Nile virus activity. Emerging Infectious Diseases 9:641-646.

Norman, S. A. 2008. Spatial epidemiology and GIS in marine mammal conservation medicine and disease research. Ecohealth 5:257-267.

Norman, S. A., C. E. Bowlby, M. S. Brancato, et al. 2004a. Cetacean strandings in Oregon and Washington between 1930 and 2002. Journal of Cetacean Research and Management 6:87-99

Norman, S. A., S. Raverty, B. McLellan, et al. 2004b. Multidisciplinary investigation of stranded harbor porpoises (Phocoena phocoena) in Washington State with an assessment of acoustic trauma as a contributory factor (2 May-2 June 2003). U.S. Department of Commerce, National Oceanic and Atmospheric Administration Technical Memorandum, NMFS-NWR-34. 120 pp. Available from the Northwest Region Office, NOAA Fisheries, Seattle, WA. Available at http://www.nwr.noaa.gov/Marine-Mammals/WhalesDolphins-Porpoise/Dolphins-Porpoise/upload/porpoise_final.pdf (accessed 15 July 2010).

Norman, S. A., S. Raverty, E. Zabek, et al. 2011. In utero materno fetal transmission of Cryptococcus gattii in a wild stranded harbor porpoise (Phocoena phocoena) in the northeastern Pacific Ocean. Emerging Infectious Diseases 17:304-305.

Norström, M., D. U. Pfeiffer and J. Jarp. 2000. A space-time cluster investigation of an outbreak of acute respiratory disease in Norwegian cattle herds. Veterinary Preventive Medicine 47:107-119.

Olea-Popelka, F. J., J. M. Griffin, J. D. Collins, G. McGrath and S. W. Martin. 2003. Bovine tuberculosis in badgers in four areas in Ireland: Does tuberculosis cluster? Preventive Veterinary Medicine 59:103-111.

Paré, J., T. E. Carpenter and M. C. Thurmond. 1996. Analysis of spatial and temporal clustering of horses with Salmonella krefeld in an intensive care unit of a veterinary hospital. Journal of the American Veterinary Medical Association 209:626-628.

Read, A. J., and K. A. Tolley. 1997. Postnatal growth and allometry of harbour porpoises from the Bay of Fundy. Canadian Journal of Zoology 75:122-130.

Rowles, T. K., L. S. Schwacke, R. S. Wells, et al. 2011. Evidence of susceptibility to morbillivirus infection in cetaceans from the United States. Marine Mammal Science 27:1-19. 
Viel, J.-F., N. Floret and F. Mauny. 2005. Spatial and space-time scan statistics to detect low rate clusters of sex ratio. Environmental and Ecological Statistics 12:289-299.

Ward, M. P., and R. T. F. Armstrong. 2000. Time-space clustering of reported blowfly strike in Queensland sheep flocks. Preventive Veterinary Medicine 43:195-202.

Ward, M. P., and T. E. Carpenter. 2000a. Analysis of time-space clustering in veterinary epidemiology. Preventive Veterinary Medicine 45:225-237.

Ward, M. P., and T. E. Carpenter. 2000b. Techniques for analysis of disease clustering in space and in time in veterinary epidemiology. Preventive Veterinary Medicine 45:257-284.

Williams, R., S. Gero, L. Bejder, et al. 2011. Underestimating the damage: Interpreting cetacean carcass recoveries in the context of the Deepwater Horizon/BP incident. Conservation Letters 4:1-6.

Received: 30 September 2010

Accepted: 5 May 2011 